\title{
Tribological behaviour of the green anode paste with a steel plate at $150{ }^{\circ} \mathrm{C}$
}

\author{
Stéphane THIBODEAU ${ }^{1}$, Houshang D. ALAMDARI ${ }^{1,2}$, Donald P. ZIEGLER ${ }^{3}$, Mario FAFARD ${ }^{1, *}$ \\ ${ }^{l}$ NSERC/Alcoa Industrial Research Chair MACE ${ }^{3}$ and Aluminium Research Centre-REGAL, Laval University, Québec, QC, GIV 0A6, \\ Canada \\ ${ }^{2}$ Department of Mining, Metallurgical and Materials Engineering, 1065 avenue de la Médecine Laval University, Quebec, QC, G1V 0A6, \\ Canada \\ ${ }^{3}$ Alcoa Primary Metals, Alcoa Technical Center, 100 Technical Drive Alcoa Center, PA 15069-0001, USA \\ Received: 12 December 2013 / Revised: 19 March 2014 / Accepted: 10 May 2014 \\ (C) The author(s) 2014. This article is published with open access at Springerlink.com
}

\begin{abstract}
In order to accurately predict the mechanical behaviour of paste during forming process, the friction law between the carbon paste and the mould wall is an important parameter to be determined. This paper presents the tribological behaviour of the lubricated paste/steel interface subjected to high stress conditions at the anode forming temperature of $150{ }^{\circ} \mathrm{C}$. A method to characterize the tribological behaviour has been developed and an apparatus was built. The method is based on the comparison of two successive experiments. In the first experiment, the paste is in contact with the friction plate. In the second one, a layer of Teflon is placed under the paste in order to excite another parameter thereby allowing the identification of the friction coefficient between the paste and steel wall. These experiments were performed with a paste under different normal loads. The static and kinetic friction coefficients of the Teflon/steel, steel/steel and paste/steel interfaces have been estimated. The static and kinetic friction coefficients of the Teflon/steel are respectively 0.17 and 0.13 . The steel/steel friction coefficients were evaluated twice which gave a static coefficient that varies between 0.22 and 0.30 . The kinetic coefficient varies between 0.18 and 0.25 . The static and kinetic paste/steel friction coefficients obtained from both experiments are clearly similar. Their values are 0.15 and 0.13 respectively.
\end{abstract}

Keywords: carbon paste; high stresses; high temperature; friction; paste/steel interface; tribological behaviour

\section{Introduction}

The aluminium is produced using Hall-Héroult process, which consists of electrolysing aluminium oxide $\mathrm{Al}_{2} \mathrm{O}_{3}$ dissolved in a molten salt bath [1-4]. A Hall-Héroult aluminium reduction cell is a steel container lined with refractory materials which included electrodes: carbon anode blocks and graphitized cathodes blocks. A good quality anode has many positive impacts including helping improving their performance in aluminium reduction cells. It also allows handling the blocks with reducing the risk of

* Corresponding author: Mario FAFARD.

E-mail: mario.fafard@gci.ulaval.ca damage. The challenge of the industry in regard to obtaining a good quality anode partially lies in the forming process.

The anode blocks are manufactured either by vibrocompaction or pressing process [1-3]. In most carbon plants, the vibrocompaction is used to give the suitable form to the carbon paste (Fig. 1). The paste is poured into a mould, which is fixed on a vibrating table and a dead weight is place on the carbon paste. The forming process duration is usually around one minute at a constant temperature of $150{ }^{\circ} \mathrm{C}$. Eccentric weights, fixed under the vibrating table, are rotating counterwise at a frequency of $25 \mathrm{~Hz}$. The developed force is oriented only in the vertical direction and the maximum pressure transmitted to 


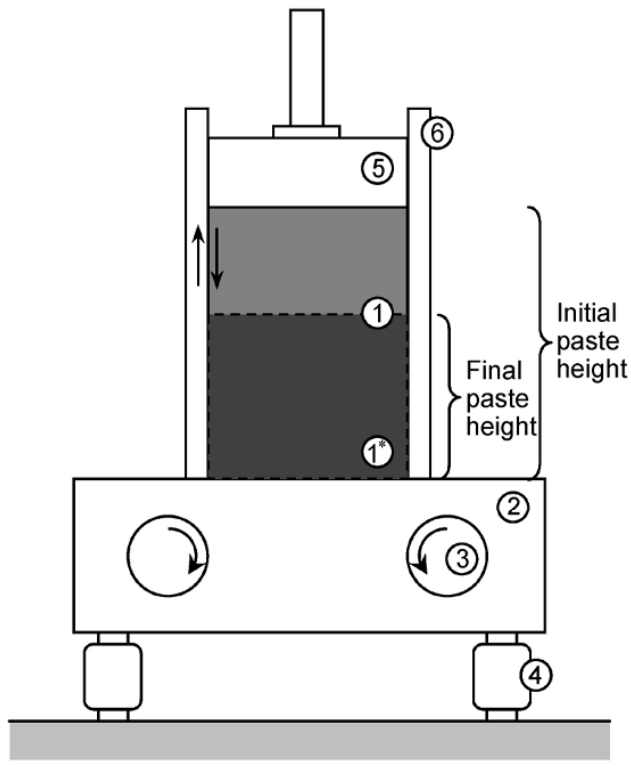

Fig. 1 Schematic representation of the vibratory compactor: 1. carbon paste $\left(1^{*}\right.$ - compressed $) ; 2$. vibrating table; 3 . eccentric weights; 4 . suspensions; 5 . dead weight; 6 . mould wall.

the paste has been estimated in this laboratory to be $3 \mathrm{MPa}$. The forming by pressing is done at the same temperature but requires a higher level of energy. The applied pressure can reach more than $60 \mathrm{MPa}$. The loading rate is unknown. According to both processes, the paste undergoes large deformation (strain) and its height is basically reduce by two; the final paste height reaches around $60 \%$ of the initial height.

The aluminium industry faces to some difficulties in the anode forming process. During the pressing of the carbon paste, the friction at the mould/paste interface plays an important role on the compaction process. The friction generates shear stress into the paste during the pressing process, which leads to fabrication defects in the anodes. The friction of the carbon paste with the slot and stub hole formers also restricts the paste displacement during the forming process, which contributes to increase undesirable density gradients through the anode. The non-uniform density decreases the anode performance in the smelting pot increasing the aluminium production cost [1-3].

Finite element simulation, using an appropriate constitutive law, can be used to optimize the forming parameters and improve the anode quality. Chaouki et al. [5] have simulated the pressing process of the green carbon paste within a rigid mould. The nonlinear compressible viscoplastic constitutive law gave good results. The simulation is based on a macroscopic model capable of predicting the mechanical behaviour of the paste. Of course, the tribological behaviour is an important parameter to feed the model for the simulation. This information is useful to manage the stresses within the paste near the interface with the mould. Therefore, the paste strains can be predicted and then, the paste density can be mapped. However, a Coulomb model with a friction kinetic coefficient of 0.1 has been arbitrarily chosen because of the lack of information in the literature in regard to the tribological behaviour of the green anode paste.

Since da Vinci and Amontons have discovered the friction phenomenon, a large number of works have been published on this topic. Currently, there exist several models that have been developed to predict friction behaviour. Tresca model, which is used and well described by Pierret et al. [6], took into account the material yield stress. Static and dynamic models, which have a temporal dependency, were also developed in order to improve simulations. Karnopp [7] proposed a static model developed to detect the sticking and sliding states and adapt the equations that describe the friction behaviour. On the other hand, Dahl [8] developed a model for the purpose of simulating the dynamic friction. Both models take into account the Stribeck effect, which considers the velocity dependency to be continuous as shown in Fig. 2 taken from Ref. [9]. Nevertheless, the most common model has been mostly developed and popularized by CharlesAugustin de Coulomb [10]. Indeed, this model is widely used due to its simplicity and its ability to properly predict the friction behaviour. It presents a linear relation between the friction force and the

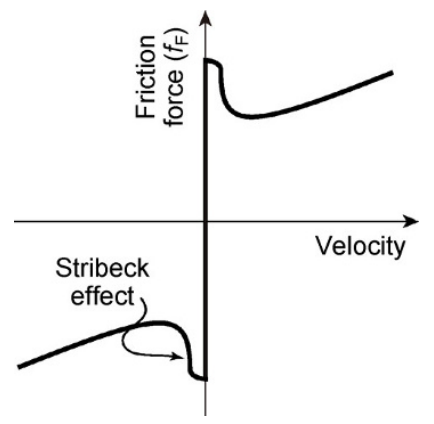

Fig. 2 Schematic representation of Stribeck effect [9]. 
normal applied force. The static and kinetic friction coefficients are considered constant independently of the velocity and normal applied load. Moreover, they are easily identifiable according to the curve of friction force as a function of the displacement.

A number of standard methods have been established to determine the friction coefficients for specific conditions. As examples, there are the ASTM-D6425, ASTM-D2047, ASTM-D1894, and ASTM-D3702 that individually cover different part of the present investigation. The ASTM-D6425 is a standard test method for measuring friction and wear properties of extreme pressure lubricating oils using SRV ${ }^{1}$ test machine. The ASTM-D2047 is a standard test method for static coefficient of friction of polish-coated flooring surfaces as measured by the James Machine. The ASTMD1894 is a standard test method for static and kinetic coefficients of friction of plastic film and sheeting. The ASTM-D3702 is a standard test method for wear rate and coefficient of friction of materials in selflubricated rubbing contact using a thrust washer testing machine. However, none of these works focus on the tribological behaviour of the green anode paste for the conditions corresponding to those of the industry. Specifically, these standards do not take into account all the technical challenges encountered in the anode forming process: high temperature together with high stress levels for a porous medium based on aggregates and binder.

The objective of this paper lies thus in development of a method to determine the static and kinetic friction coefficients at the mould/paste interface. A special apparatus has been developed with the aim of charactering the tribological behaviour in the conditions that face the carbon paste during the forming process. The apparatus allows performing the tests in a wide range of velocities and applied pressures while maintaining the interface temperature around $150{ }^{\circ} \mathrm{C}$. The influences of the relative velocity at the interface and the normal load applied were investigated. The relative velocity and the applied pressure ranged from 2 to $20 \mathrm{~mm} / \mathrm{s}$ and from 0.5 to $8 \mathrm{MPa}$, respectively. Based on the Coulomb model, the friction coefficient is a linear relation between normal and tangential forces. The coefficients are independent of the velocity

${ }^{1}$ SRV means oscillating friction and wear in German language. and applied pressure. The range of pressure used helps reducing a possible error of a unique test performed at a specific pressure and improves the correlation between normal and tangential forces. The carbon paste friction coefficients (static and kinetic) were then evaluated using the methodology described hereafter.

\section{Materials and methods}

\subsection{The carbon paste preparation}

The anode paste is made by mixing calcined petroleum coke and coal tar pitch. The calcined coke is included in the recipe under two forms: large aggregates and fine particles (fines). The coke aggregates respect the size distribution shown in the Table 1 [11]. The fines are produced by ball milling of calcined coke until a Blaine umber of 4200 is reached. The paste recipe was based on one currently used by the industry [11]. Table 1 presents the details of the recipe prepared within this study. The dry percentage corresponds to the fraction of each coke size excluding the coal tar pitch. The mix percentage indicates the fraction of each constituent within the paste including coal tar pitch.

All the ingredients are mixed together using a mixer installed in a furnace in order to prepare and homogenize the paste while maintaining its temperature at $178{ }^{\circ} \mathrm{C}$ [11]. The aggregates and fines were first preheated during 120 minutes to eliminate the moisture. Coal tar pitch was then added to the hot coke particles and heated for another 30 minutes. Finally, all the raw materials are mixed during 10 minutes to obtain a uniform mixture (for more details, refer to

Table 1 Recipe of the paste used for the friction tests.

\begin{tabular}{cccc}
\hline $\begin{array}{c}\text { Aggregate sizes } \\
\text { (US Mesh) }\end{array}$ & Mass (g) & \% dry & \% mix \\
\hline$-4+8$ & 62.2 & 21.8 & 17.9 \\
$-8+14$ & 28.4 & 9.9 & 8.1 \\
$-14+28$ & 33.0 & 11.5 & 9.4 \\
$-28+48$ & 36.2 & 12.6 & 10.3 \\
$-48+100$ & 26.1 & 9.1 & 7.5 \\
$-100+200$ & 30.4 & 10.6 & 8.7 \\
Fines & 70.4 & 24.5 & 20.1 \\
Pitch & 63.0 & - & 18.0 \\
Total & 350 & 100 & 100 \\
\hline
\end{tabular}


Ref. [11]). Azari et al. [12] have demonstrated that the mixing time and the temperature chosen are the optimal conditions to obtain the maximum density of the paste.

\subsection{Experimental setup}

The friction tests are performed by means of an apparatus that controls independently both the normal load and the tangent velocity (Fig. 3). The two hydraulic actuators (MTS 244.31) with a capacity of $250 \mathrm{kN}$ were used. The actuator A applies the desired compressive load on the paste, confined in a steel mould. The actuator B controls the horizontal velocity of the paste by applying a tension in a cable attached to the mould (4 on Fig. 3). A tensed cable attaches the mould to the cylinder. This cable is redirected to the actuator B by the means of a ball bearing pulley (four inches in diameter) in order to minimize the loss in tension load. A linear variable differential transformer (LVDT) is installed behind the mould (extension mode) to record the horizontal displacement.

The pulley support and the mount within which the mould will move are presented on Fig. 4. The pulley and the mount are fixed on a large rigid beam located under the two hydraulic cylinders. The pulley is simply inserted through the support (3 on Fig. 3 ) by means of bearings and only one axis of rotation is allowed for the pulley. The mount is also designed to

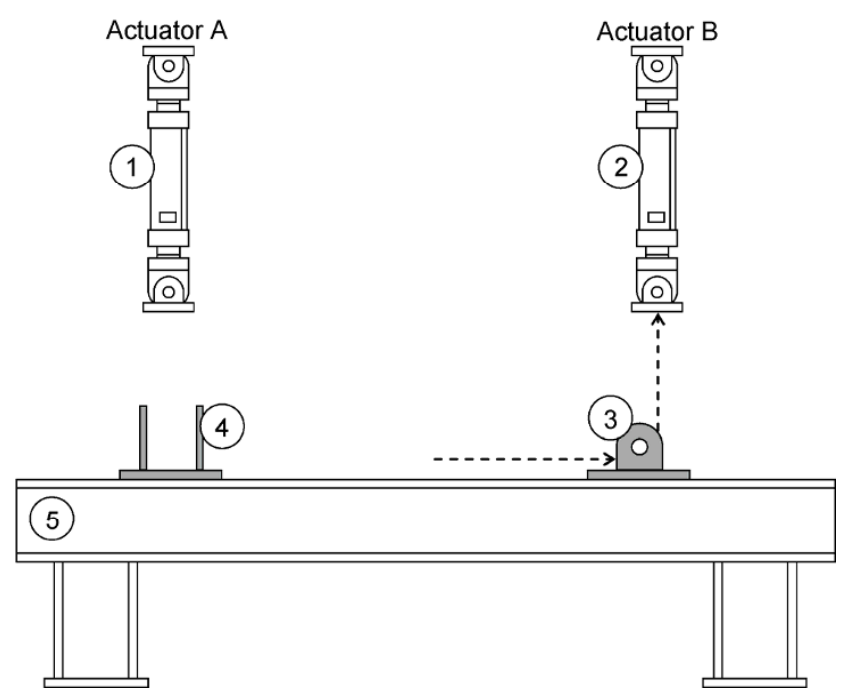

Fig. 3 Schematic representation of the global setup used for the friction tests: 1. loading actuator; 2. pulling actuator; 3. pulley support; 4. mount of the mould; 5. rigid beam. allow the displacement in the pulling direction only. Four vertical rods, fixed to the base plate of mount, are used to guide the movement of the top plate in the load direction without blocking the desired mould translation (5 on Fig. 4). Grooves are machined under the top plate and on top of the piston block. Ball bearings, inserted in these grooves, ensure a frictionless interface in the upper section of the mount. The top plate and the piston block are heat treated in order to increase the bearing efficiency. The mould is placed on the friction plate with a Teflon (PTFE) layer in between. The form of the Teflon layer perfectly fits the mould cross section. Teflon material was chosen in order to minimize the mould friction with the plate. Although the frictionless property of the PTFE Teflon can be slightly degraded due to the high temperature test such as $150{ }^{\circ} \mathrm{C}$, this type of Teflon well resists this temperature. Figure 5 illustrates the paste/friction plate interface. The assembly described

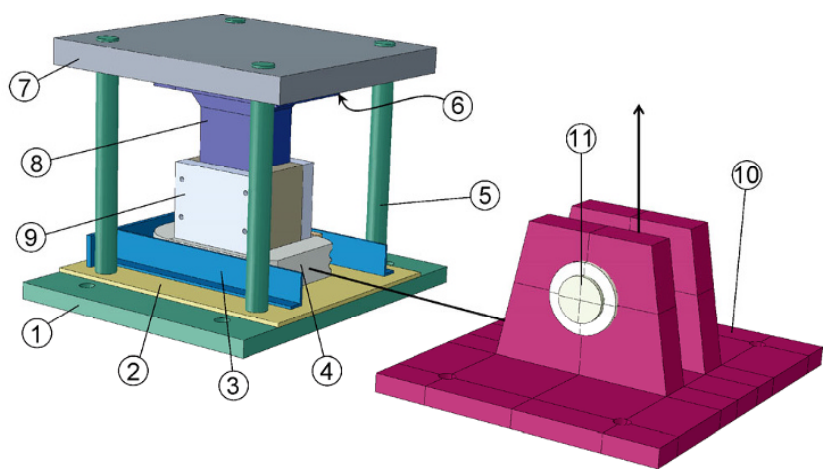

Fig. 4 The friction mould in its mount (left) and the pulley (right): 1. base plate; 2 . friction plate; 3 . mould guide; 4 . cable adaptor; 5. vertical rod; 6 . linear bearings (underneath); 7. top plate; 8. piston block; 9. mould; 10. pulley support; and 11. pulley.

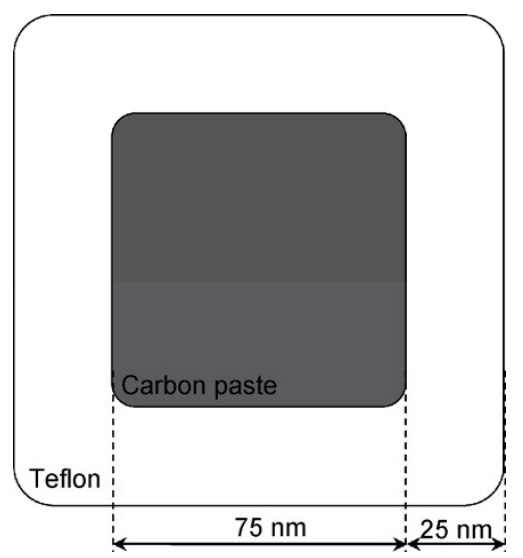

Fig. 5 Schematic of the paste/friction plate interface. 
above eliminates the vertical translation and two rotational degrees of freedom of the piston block. A guide is installed between the four rods to eliminate the third rotational degree of freedom around the vertical axis and to restrict the mould displacement to the pulling direction.

Precautions need to be taken regarding the test temperature. The steel used within the apparatus acts as a heat sink. A heating strip surrounds the mould to counteract the heat lost through the mould wall and maintain the preheated paste at $150{ }^{\circ} \mathrm{C}$. A cordierite plate and a heating plate are inserted between the beam and the base plate in order to maintain the interface at the desired temperature $\left(150 \pm 1{ }^{\circ} \mathrm{C}\right)$ during the tests. A thermocouple placed in the middle of the heating plate controls its temperature. The heating plate is turned on at the same moment as the dry coke preheating. The exposed area of the friction plate is covered with an isolating pad to reduce the temperature drop thus preventing the paste from freezing and consequently modifying the friction behaviour.

\subsection{Assembling and test procedures}

In order to perform the friction tests on the carbon paste a sequence of manipulations must be executed in a minimal amount of time to prevent the temperature variations. The mould and piston block are first preheated in a furnace. Then, the Teflon layer and mould are placed inside the cable support and rest on the friction plate. During this manipulation, a thermocouple is placed at the interface via a small groove machined at the bottom of the mould. A thin film of lubricant, made of 13 mass percent "mobilcut 102 " oil in water, is sprayed on the friction plate and inside the mould cavity then the mould is filled with the hot paste. This lubricant is similar to one used in anode industry to lubricate the mould walls before pouring the paste into the mould. The piston block, bearing balls and top plate are then put in place. Finally, the hydraulic piston is levelled and brought down on the top plate.

The test program is started once the paste/plate interface temperature is stabilized at $150 \pm 1{ }^{\circ} \mathrm{C}$. The hydraulic cylinder exerts a vertical load on the mould and maintains it for $60 \mathrm{~s}$ during which the paste creeps to reach a maximum deformation. This rest period is used to ensure obtaining stability of the paste texture at the interface with the mould. After this period, the second hydraulic actuator is activated with a constant velocity. The mould is pulled over a distance of $10 \mathrm{~mm}$. Then the stress in the cable is released, followed by the vertical load. The mould is manually replaced at its initial position and all the steps are repeated to complete the series of tests, i.e., different applied loads or the displacement rates.

Within the first series of tests, the applied pressure was kept constant at $57 \mathrm{kN}(10 \mathrm{MPa})$ and the mould velocity was varied from 2 to $20 \mathrm{~mm} / \mathrm{s}$ by an increment of $2 \mathrm{~mm} / \mathrm{s}$. The test sequence was randomly set in order to eliminate influences that could be caused by paste interface alteration. Within the second series of tests, velocity was kept constant at $10 \mathrm{~mm} / \mathrm{s}$ and the applied load varied from 2.85 to $37.05 \mathrm{kN}$ (0.5 to $6.5 \mathrm{MPa}$ ) by an increment of $2.85 \mathrm{kN}$. The test sequence however has respected the increase of the load so as not to reach an irreversible deformation of the paste surface in contact with the steel plate. The first test was repeated at the end of the series to ensure that the paste interface has not been altered during the sequence of tests.

\subsection{Characterization of the friction coefficients}

The friction was characterized according to the Coulomb model. At a constant velocity, the friction force is equivalent to the traction force $F_{\mathrm{T}}$ exerted by the hydraulic actuator that controls the paste velocity (actuator B on Fig. 3). This force is measured by the load cell integrated in the actuator B. For a given normal load, the friction force versus displacement curve is obtained (Fig. 6(a)), allowing the identification of the static and kinetic friction coefficients (Eq. (1)). For a series of test performed for different normal loads, these friction coefficients are aligned as illustrated in Fig. 6(b). The points on the curves represent the $\mu_{\mathrm{s}}$ and $\mu_{\mathrm{k}}$ values extracted from the Fig. 6(a) according to the load of each test.

$$
f_{\mathrm{F}} \begin{cases}=\mu \cdot N & \text { if } N \leqslant \text { Breakaway force } \\ =\text { constant } \leqslant \mu \cdot N & \text { if } N>\text { Breakaway force }\end{cases}
$$



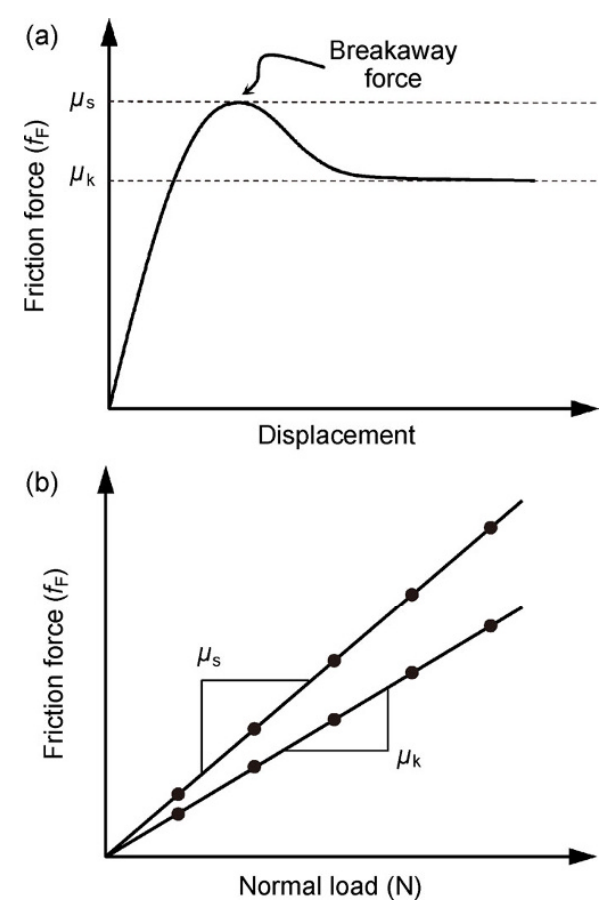

Fig. 6 Coulomb model of friction: (a) friction force in function of the displacement and (b) friction force in function of the normal force.

However, the normal force of the paste at the interface is more difficult to determine. In fact, the normal force of the paste at the interface is lower than the applied load (actuator A on the Fig. 3) due to the friction of the paste with the mould wall. An unknown part of the applied load is transmitted to the friction plate via the mould. The friction coefficients and the normal force to this interface are also unknown. In order to overcome this difficulty, a method, described below, was developed to evaluate the paste friction coefficients regardless to the forces transmitted to the friction plate through the paste and mould wall. Figure 7 illustrates the free body diagram of the friction mould.

First, a series of friction tests were performed with the paste in contact with the friction plate and a thin layer of Teflon mounted under the mould as shown in Fig. 7. This series was constituted of 13 tests with an applied load varying from 2.85 to $37.05 \mathrm{kN}$ by increment of $2.85 \mathrm{kN}$. Secondly, a similar series of tests was performed with a thin steel plate placed under the paste, thus generating a steel/steel friction instead of paste/steel friction. The traction force is then equivalent to the sum of the Teflon/steel and steel/steel friction. The two series of tests have the same boundary conditions inside the mould since a

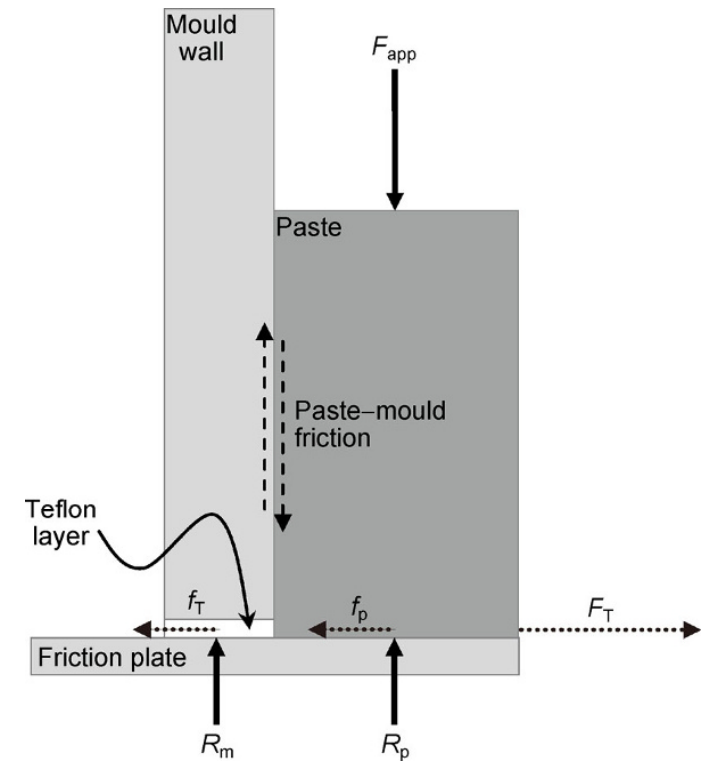

Fig. 7 Free body diagram of the mould cross section ${ }^{2}$.

same normal load was used in both cases. The force transmitted by the paste to the friction plate was therefore the same for both series of tests.

$$
\begin{gathered}
F_{\mathrm{T}}=f_{\mathrm{p}}+f_{\mathrm{T}} \\
F_{\mathrm{T} 1}=f_{\mathrm{s}}+f_{\mathrm{T}}
\end{gathered}
$$

where, $F_{\mathrm{T}}$ and $F_{\mathrm{T} 1}$ are the traction forces exerted by the actuator $B$ for the first and the second tests, respectively and $f_{\mathrm{p}}, f_{\mathrm{T}}$ and $f_{\mathrm{s}}$ are the friction forces associated to the paste, Teflon and steel respectively.

According to the Coulomb model, the friction force is defined as the friction coefficient multiplied by the normal force to the interface.

$$
f_{x}=\mu_{x / \mathrm{s}} \cdot N_{x}
$$

where $f, \mu$ and $N$ are the friction force, friction coefficient and normal force, respectively and $x$ denotes the media in contact with steel plate, i.e., paste, Teflon or steel.

The applied force $\left(F_{\text {app }}\right)$ is transmitted to the friction plate through the paste and the mould wall. The applied force is expressed as a reaction to the paste $\left(R_{\mathrm{p}}\right)$ and mould $\left(R_{\mathrm{m}}\right)$.

$$
F_{\text {app }}=R_{\mathrm{p}}+R_{\mathrm{m}}
$$

\footnotetext{
${ }^{2}$ The forces identified with a "upper case $F$ ", "upper case $R$ " and "lower case $f$ ", are related to the actuator, reaction and friction forces respectively.
} 
Based on Eq. (4) and the force definitions, the traction forces $\left(F_{\mathrm{T}}\right.$ and $\left.F_{\mathrm{T} 1}\right)$ can be rewritten:

$$
\begin{aligned}
& F_{\mathrm{T}}=R_{\mathrm{p}} \cdot \mu_{\mathrm{p} / \mathrm{s}}+R_{\mathrm{m}} \cdot \mu_{\mathrm{T} / \mathrm{s}} \\
& F_{\mathrm{T} 1}=R_{\mathrm{p}} \cdot \mu_{\mathrm{s} / \mathrm{s}}+R_{\mathrm{m}} \cdot \mu_{\mathrm{T} / \mathrm{s}}
\end{aligned}
$$

By subtracting Eq. (7) from Eq. (6), the paste reaction force, $R_{\mathrm{p}}$, becomes:

$$
R_{\mathrm{p}}=\frac{F_{\mathrm{T}}-F_{\mathrm{T} 1}}{\mu_{\mathrm{p} / \mathrm{s}}-\mu_{\mathrm{s} / \mathrm{s}}}
$$

By replacing Eq. (5) and Eq. (8) into Eq. (7), one may obtain:

$$
F_{\mathrm{T} 1}=F_{\mathrm{app}} \cdot \mu_{\mathrm{T} / \mathrm{s}}+\frac{F_{\mathrm{T}}-F_{\mathrm{T} 1}}{\mu_{\mathrm{p} / \mathrm{s}}-\mu_{\mathrm{s} / \mathrm{s}}} \cdot\left(\mu_{\mathrm{s} / \mathrm{s}}-\mu_{\mathrm{T} / \mathrm{s}}\right)
$$

Then the paste/steel friction coefficient can be expressed as a function of the known parameters:

$$
\mu_{\mathrm{p} / \mathrm{s}}=\frac{F_{\mathrm{T}}-F_{\mathrm{T} 1}}{F_{\mathrm{T} 1}-F_{\mathrm{app}} \cdot \mu_{\mathrm{T} / \mathrm{s}}} \cdot\left(\mu_{\mathrm{s} / \mathrm{s}}-\mu_{\mathrm{T} / \mathrm{s}}\right)+\mu_{\mathrm{s} / \mathrm{s}}
$$

The three forces $\left(F_{\mathrm{app}}, F_{\mathrm{T}}\right.$ and $\left.F_{\mathrm{T} 1}\right)$ are measured using the load cell of the actuators. The friction coefficients of the Teflon/steel and steel/steel were characterized separately using the same apparatus and the temperature was factored in as well. The friction coefficients were characterized at $150{ }^{\circ} \mathrm{C}$.

Another experiment was performed in order to validate the paste/steel friction coefficients found with the previous approach by interchanging the Teflon and steel layers placed under the mould and the paste. In this new setup, Teflon was placed under the paste and the steel under the mould as show in Fig. 8 (bottom setup in the "comparative tests" section). The values of the paste friction test $\left(F_{\mathrm{T}}\right)$ were reused. Equation (6) is rewritten and the equation of the comparative test becomes:

$$
\begin{gathered}
F_{\mathrm{T}}=R_{\mathrm{p}} \cdot \mu_{\mathrm{p} / \mathrm{s}}+F_{\mathrm{app}} \cdot \mu_{\mathrm{T} / \mathrm{s}}-R_{\mathrm{p}} \cdot \mu_{\mathrm{T} / \mathrm{s}} \\
F_{\mathrm{T} 2}=R_{\mathrm{p}} \cdot \mu_{\mathrm{T} / \mathrm{s}}+F_{\text {app }} \cdot \mu_{\mathrm{s} / \mathrm{s}^{*}}-R_{p} \cdot \mu_{\mathrm{s} / \mathrm{s}^{*}}
\end{gathered}
$$

Equation (11) is added to Eq. (12):

By replacing Eq. (13) into Eq. (11), one may isolate the paste/steel friction coefficient:

$$
\begin{gathered}
R_{\mathrm{p}}=\frac{F_{\mathrm{T}}+F_{\mathrm{T} 2}-F_{\mathrm{app}} \cdot\left(\mu_{\mathrm{s} / \mathrm{s}^{*}}+\mu_{\mathrm{T} / \mathrm{s}}\right)}{\mu_{\mathrm{p} / \mathrm{s}}-\mu_{\mathrm{s} / \mathrm{s}^{*}}} \\
\mu_{\mathrm{p} / \mathrm{s}}=\frac{\left(F_{\mathrm{T}}+F_{\mathrm{T} 2}\right) \cdot \mu_{\mathrm{T} / \mathrm{s}}-F_{\mathrm{T}} \cdot \mu_{\mathrm{s} / \mathrm{s}^{*}}-F_{\mathrm{app}} \cdot \mu_{\mathrm{T} / \mathrm{s}}^{2}}{F_{\mathrm{T} 2}-F_{\mathrm{app}} \cdot \mu_{\mathrm{s} / \mathrm{s}^{*}}}
\end{gathered}
$$

The friction coefficients of the Teflon/steel and the steel/steel interfaces have been obtained by performing a series of friction tests using an empty mould. The piston was blocked by means of spacers in order to perform the tests without paste. A thin layer was placed under the mould. The steel/steel friction coefficient needed to be determined twice because the apparatus behaved differently depending on where the steel layer is placed (under the paste or the mould). In order to reproduce this condition, steel/ steel friction coefficient was determined a second time using two layers that were placed under the mould and the paste. Figure 8 summarized the global approach used within this investigation by showing the interface setups. Figure 9 presents a flow chart combining both experiments.

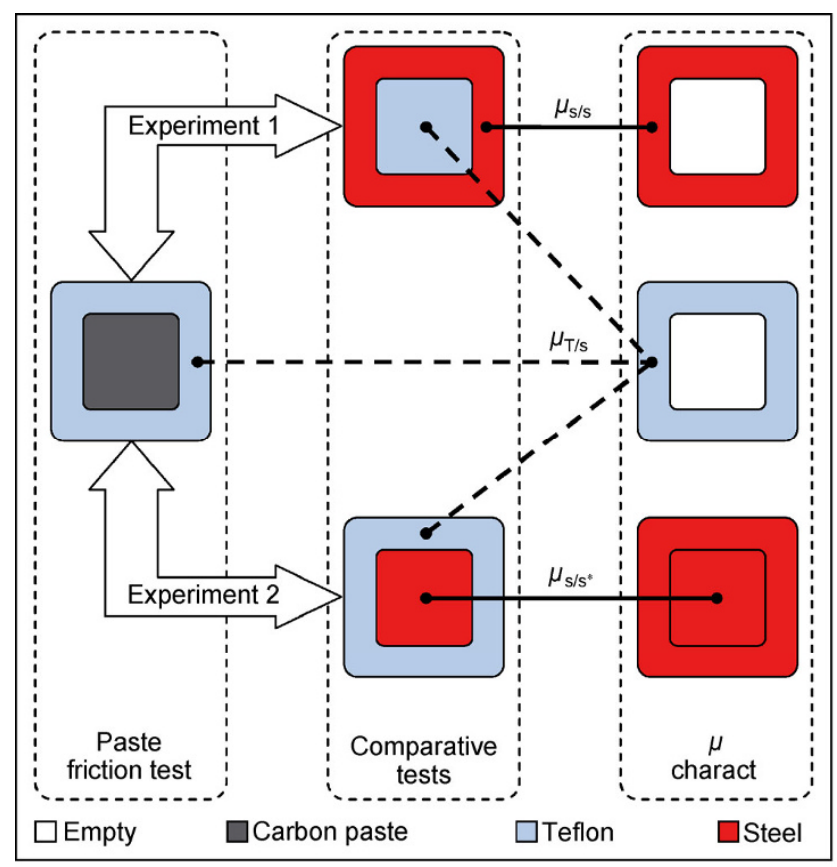

Fig. 8 Approaches employed within this investigation presented through the interface areas in contact with the friction plate (Note: $\mu$ charact are the tests used to characterize the steel/steel and Teflon/steel friction coefficients). 


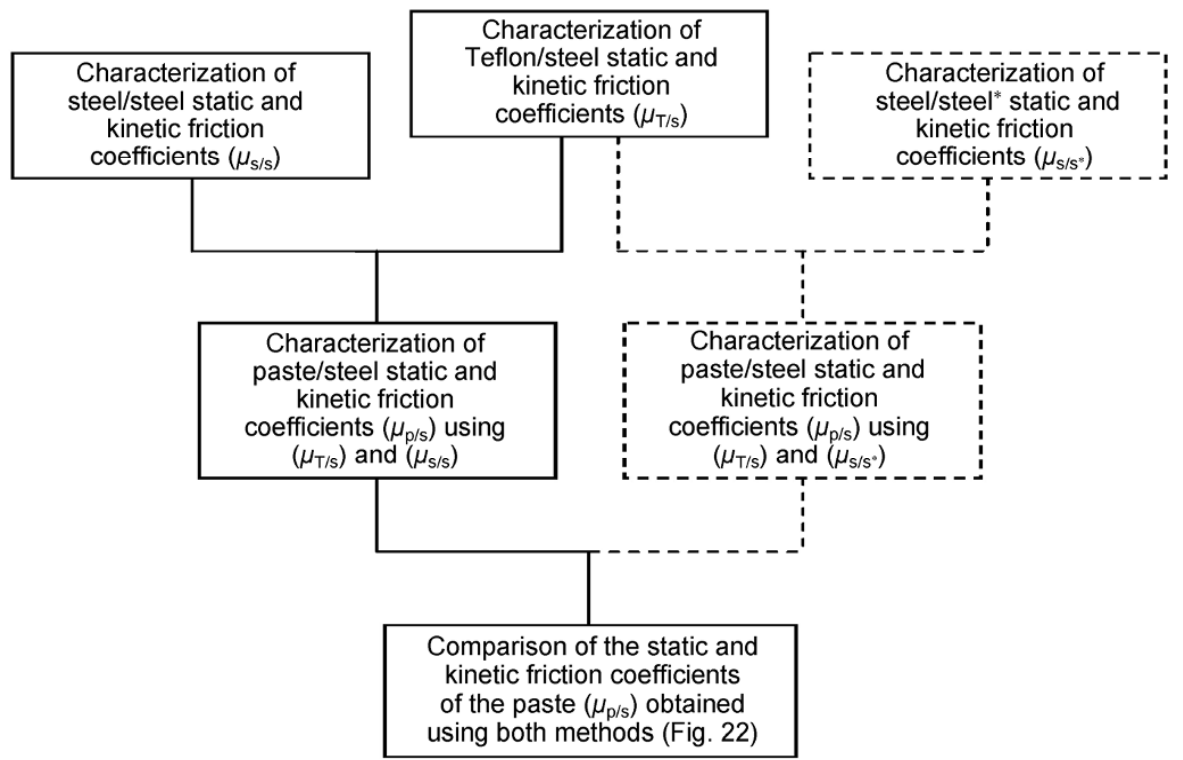

Fig. 9 Flow chart of the test procedures: first row—characterization of the Teflon/steel and steel/steel interface, second row—characterization of the paste/steel interface using two approaches, and last row-comparison of the two paste/steel friction behaviours.

\section{Results and discussion}

\subsection{Influence of velocity and applied load on friction behaviour (validation of the Coulomb model)}

In order to study the influence of the displacement rate on the friction behaviour, a series of ten friction tests were performed. The velocity varied randomly from 2 to $20 \mathrm{~mm} / \mathrm{s}$. The applied load on the paste was held constant at $57 \mathrm{kN}$ during each test. Figure 10 presents a typical curve (displacement rate of $10 \mathrm{~mm} / \mathrm{s}$ ) of the traction required as a function of the displacement over the whole length. The static friction coefficient was calculated from the breakaway force of each curve inside the first millimetre of displacement. The kinetic friction coefficient should be evaluated from the plateau that followed this peak. The results however show a slight increase of the force with the mould displacement. This variation is caused by a slight decrease in temperature of the friction plate despite the taken precautions. The coal tar pitch may change the viscosity with temperature resulting in a modification of its friction behaviour. For this reason, the kinetic friction coefficients were determined from the forces corresponding to a displacement of $1.5 \mathrm{~mm}$ (vertical dashed line).

Figure 11 shows the static and kinetic friction forces obtained for each displacement rate. These

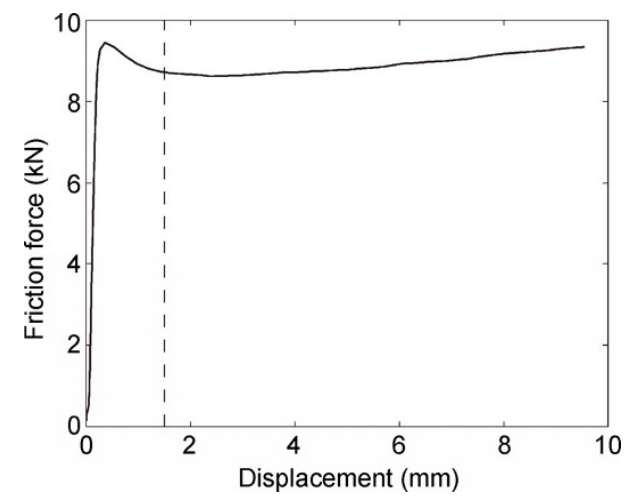

Fig. 10 Friction tests to characterize the influence of the relative velocity between the carbon paste and the steel plate: friction force as function of the displacement.

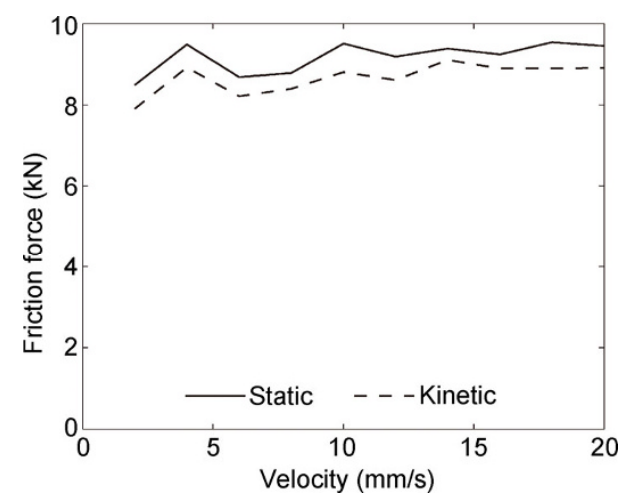

Fig. 11 Static and kinetic friction forces in function of the mould velocity.

results indicate that the displacement rate does not significantly affect the friction behaviour of the carbon 
paste considering the velocity range used in this study. The static and kinetic friction forces demonstrate constancy relative to the mould velocity. As the applied force was the same for the entire series, the friction coefficients should be constant. This is compatible with the Coulomb model, which is independent of the relative velocity at the interface.

The influence of the normal force on friction force is shown in Fig. 12. In this case, the applied load was incremented by $2.85 \mathrm{kN}$ to increase from 2.85 to 37.05 and a velocity of $10 \mathrm{~mm} / \mathrm{s}$ was kept constant. The first test $(2.85 \mathrm{kN})$ was repeated at the end of the series to evaluate the paste alteration effect on the friction behaviour.

The traction force as a function of the displacement of the mould for each normal loading was plotted in Fig. 12. The repeated test is presented with a dash line $\left(2.85 \mathrm{kN}^{(\mathrm{r})}\right)$. The superposition of the two curves, corresponding to the first and last tests $(2.85 \mathrm{kN})$, demonstrates that the effect of paste alteration on friction coefficient is negligible. All curves show a clear plateau after the breakaway force for each test, indicating that the paste does not undergo freezing suggesting that the temperature of the friction plate was more uniform during this series. Friction forces for both static and kinetic values change linearly with normal force, as shown in Fig. 13. The red lines present the linear regression curves. The regressions have been force to cross zero because no friction force is developed without normal force.

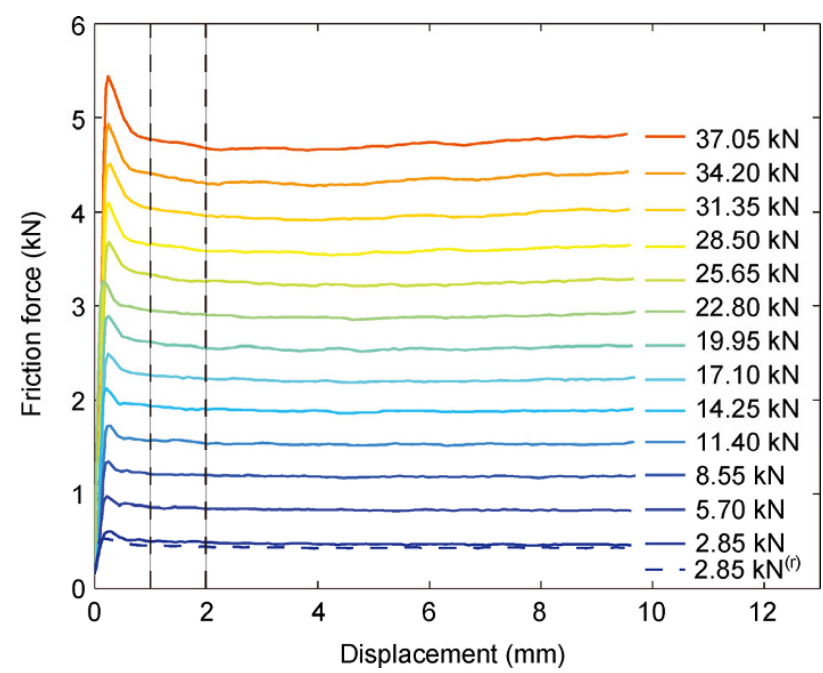

Fig. 12 Friction tests to characterize the influence of the normal applied load: friction force in function of the displacement.

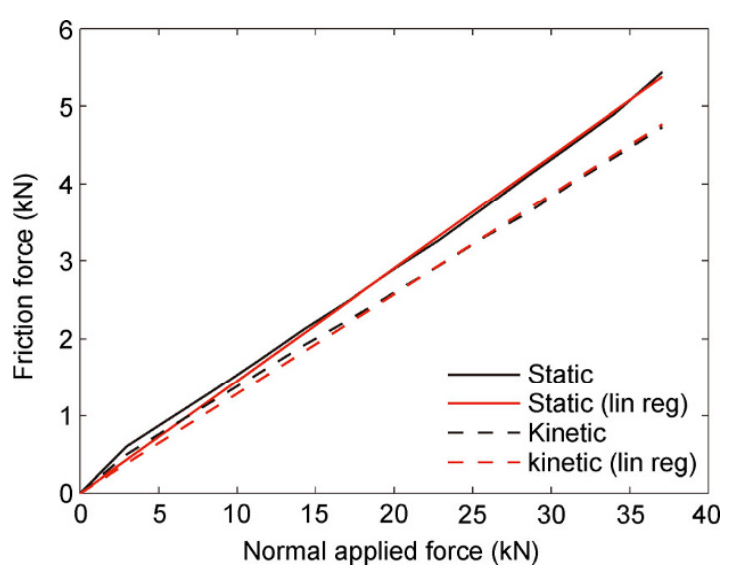

Fig. 13 Static and kinetic friction forces in function of the applied force.

Based on the last two experiments, the Coulomb model is considered valid to characterize the tribological behaviour of the green anode paste at $150{ }^{\circ} \mathrm{C}$. According to this model, the static and kinetic friction coefficients could be obtained from these curves if the portion of the normal load, which is transferred on the mould wall, is subtracted from the applied normal force. In order to take into account this frictional force on the mould wall, the comparative method presented in Section 2.4 has to be followed and the friction coefficients of the Teflon/steel and steel/steel interface needed to be evaluated beforehand.

\subsection{Characterization of the Teflon/steel and steel/ steel friction coefficients}

Within this section, the results related to the characterization of friction coefficients at Teflon/steel and steel/steel interfaces are presented. The same apparatus was used in order to obtain the curves of friction force as a function of mould displacement. The same temperature $\left(150{ }^{\circ} \mathrm{C}\right)$ and lubrication method were used as for the previous Section 3.1. The mould velocity was set at $10 \mathrm{~mm} / \mathrm{s}$ for all tests. A series of friction tests with different normal loads was performed to characterize each material. The results were treated in the same way as for the influence of the normal applied load in the second part of the Section 3.1. In this case, the normal load to the interface corresponds to the applied load by the actuator. Different strategies were used to ensure that the applied load be transmitted to the interface only through the material to be characterized. 
The Teflon/steel friction coefficients were characterized using an empty mould (without paste). The piston block was resting on the mould by means of spacers. The Teflon layer was placed under the mould so that nothing else is in contact with the friction plate. The Teflon layer shape corresponds to a cross section (top view) of the mould, i.e., empty square shape (see Fig. 8). The series was consisting in six friction tests with applied forces ranging from 2.85 to $17.10 \mathrm{kN}$.

Figure 14 presents the friction forces as a function of the mould displacement for the six tests with different loads. The static friction coefficient was determined from the breakaway force of each curve. The evaluation of the kinetic friction coefficient was based on the mean value of the curve segments delimited by the vertical dash lines, chosen due to the plateau. The friction forces were plotted as a function of the applied force in Fig. 15 (black curves). Once again, the zero was forced for both static and kinetic linear regressions (red lines). The static and kinetic friction coefficients of the Teflon identified by the linear regression are 0.17 and 0.13 respectively. The friction values obtained respect those suggested in the literature (0.05-0.2) [13].

The steel/steel friction coefficients were characterized twice due to an unexpected behaviour. The first characterization followed the same method as used for the Teflon. Figure 16 presents the curves of the friction force as a function of the mould displacement corresponding to the six different applied loads. The

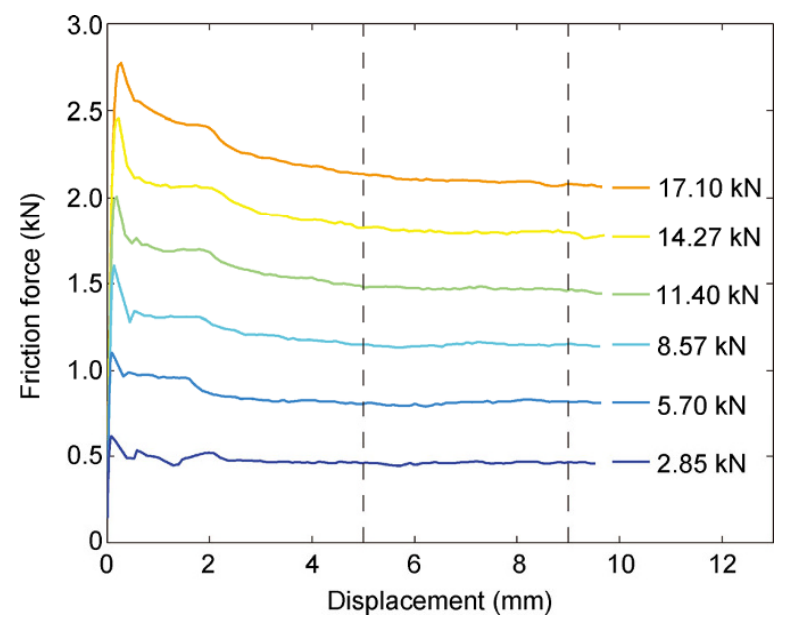

Fig. 14 Friction tests to characterize the Teflon/steel friction coefficients.

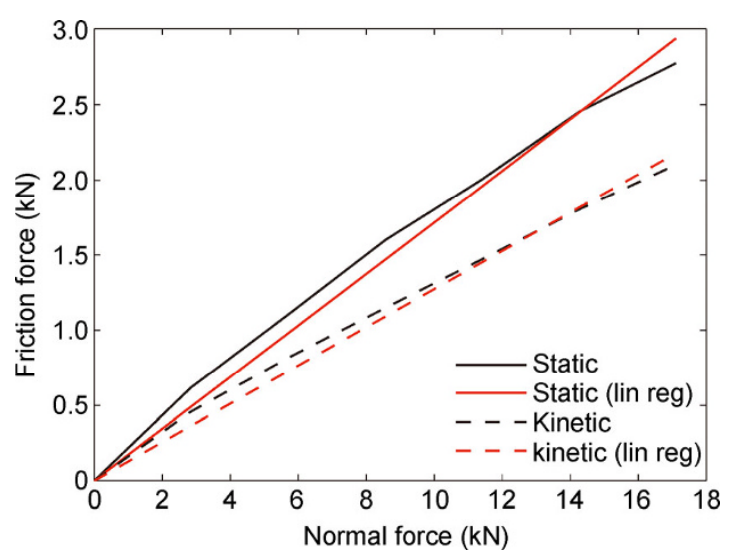

Fig. 15 Static and kinetic friction forces of the Teflon/steel interface as functions of the applied force.

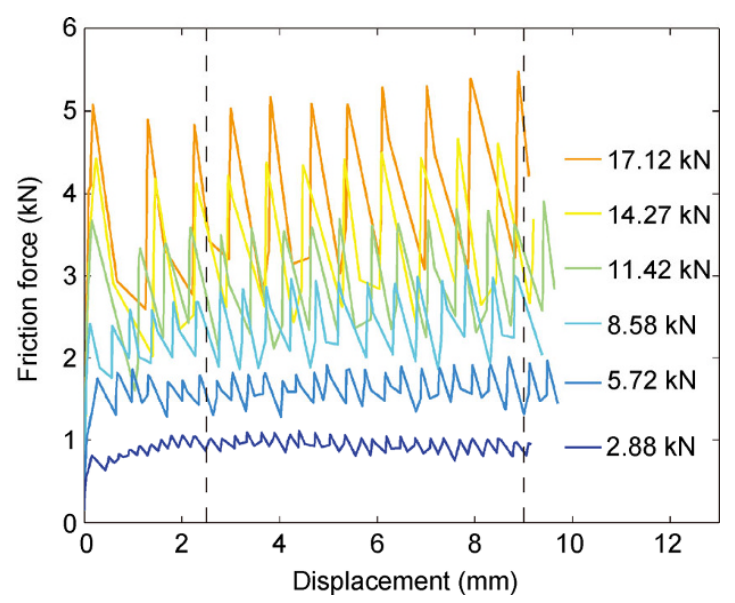

Fig. 16 Friction tests to characterize the steel/steel friction coefficients.

static coefficient was evaluated from the first peak, within a displacement distance of $0.5 \mathrm{~mm}$, of each curve. The kinetic friction coefficient of the steel was evaluated according to the mean value of the curve delimited by the two vertical dash lines.

In this case, the mould demonstrated a stick-slip behaviour giving serrated curves. The amplitude of the serrated curve increases with the applied load. The stick-slip behaviour can be a consequence of the lubricant escaping due to the squeezing forces as explain Hwang and Zum Gahr [14]. The friction force increases until the breakaway force and then the movement becomes possible. The lubricant regains its place by suction and this cycle is repeated. The friction coefficients have been considered as two different media in view of the Hwang and Zum Gahr's work. The lubricant follows different paths before being escaped from under the steel layers. The 
stick-slip behaviour might also be caused by the mechanical interaction between the steel layer and the friction plate that are unpolished. Under a large loading, the two steel pieces intercalate into each other. This creates anchors that block the tangential relative movement (stick) until the tangential force is sufficiently large to release these anchors (slip).

Again, the friction force at the steel/steel interface as a function of the normal applied force was plotted in Fig. 17 (black curves). The linear regressions are presented with the red curves. The static curve should be higher than the kinetic one for any normal applied load. Due to the difficulty to capture the exact values from the Fig. 16, the friction forces might be inadequately evaluated. However, the linear tendency shows that the evaluations of these forces are acceptable and the linear regressions bring a certain level of correction to these misevaluated values. The slopes reveal static and kinetic friction coefficients of 0.30 and 0.25 , respectively for the empty square shape layer of steel in contact with the friction plate.

The second characterization was performed by adding a square layer of steel in order to fill the centre of the layer (empty square shape) used in the previous characterization. Obviously, the mould was filled with the hot paste to apply a load on this added layer. Therefore, the two layers of steel were fully covering the paste and mould areas at the interface.

Figure 18 presents the friction force as a function of displacement for the 16 tests performed to characterize the steel/steel interface for this particular condition. The serrated curves demonstrate a stick-slip behaviour of the mould during the tests. As before, this behaviour

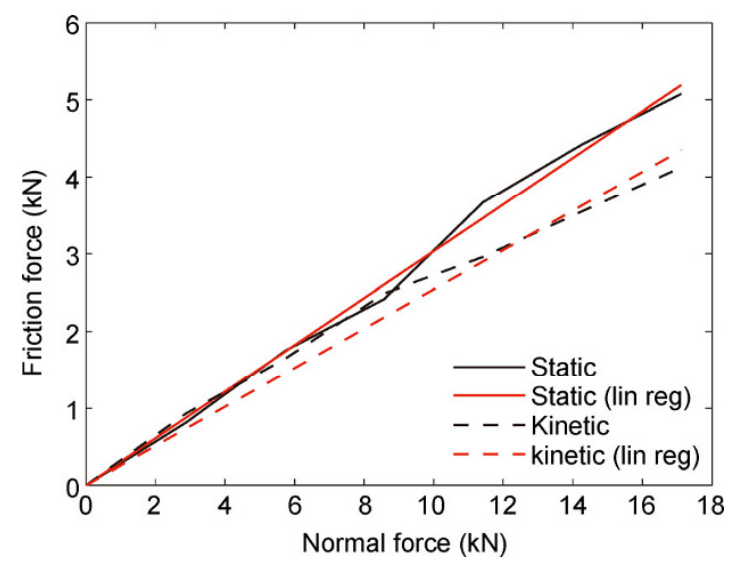

Fig. 17 Static and kinetic friction forces of the steel/steel interface as functions of the applied force.

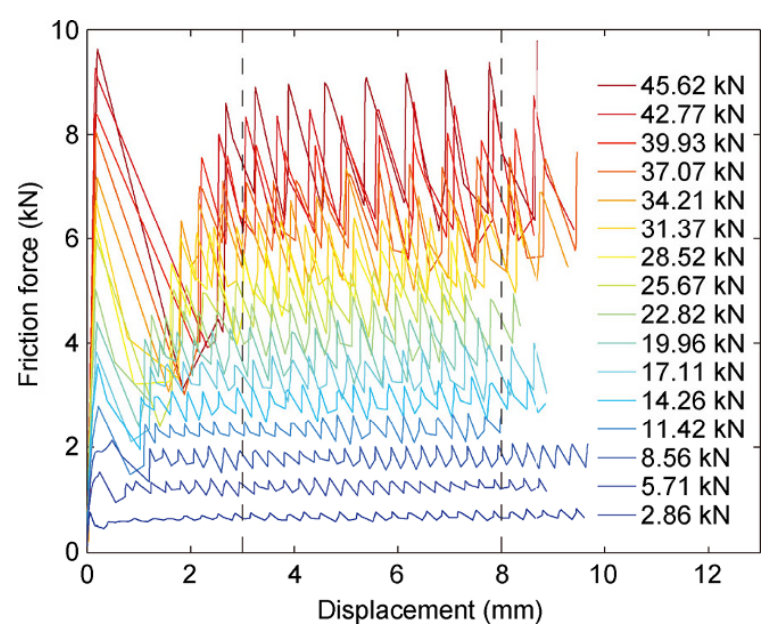

Fig. 18 Friction tests to characterize the steel/steel ${ }^{*}$ friction coefficients following the second setup.

was accentuated as the applied load increased. However, the first maxima are clearly separated from the serrated displacement pattern starting around $3 \mathrm{~mm}$. The values used to determine the static friction coefficient correspond to these maxima. The kinetic friction coefficient was obtained from the mean values of the curves delimited by the vertical dash line.

Figure 19 presents the friction force as a function of the applied load as well as the linear regression for both static and kinetic cases. Again, the linear tendency of the kinetic friction shows that the friction forces obtained from Fig. 18 are adequate. For the present case, the static and kinetic friction coefficients were measured to be 0.22 and 0.18 , respectively.

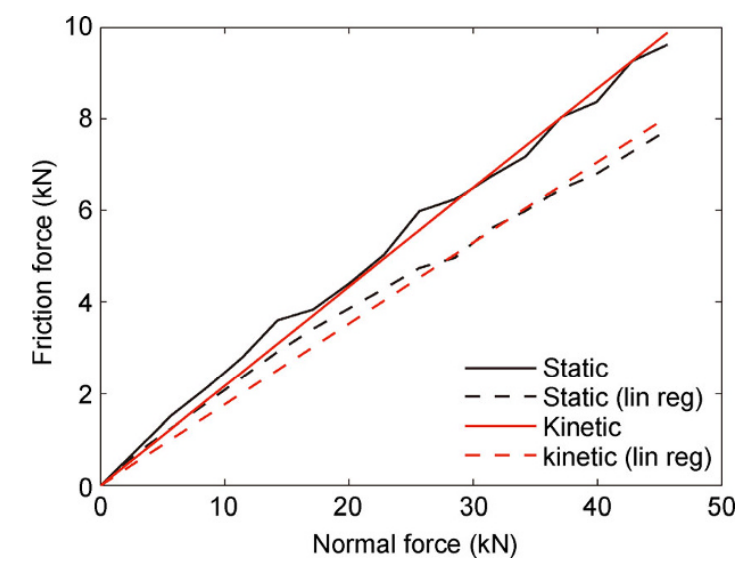

Fig. 19 Static and kinetic friction forces of the steel/steel ${ }^{*}$ interface as a function of the applied force using the second setup.

\footnotetext{
${ }^{3} \mathrm{Steel} / \mathrm{steel}^{*}$ and s/s${ }^{*}$ (starry) are related to the second characterisation of the steel/steel interface (two layers).
} 
For both characterizations of the steel/steel friction coefficients, the obtained values are somewhat higher than those reported in the literature. In fact, many sources propose a steel/steel friction kinetic coefficient that ranges between 0.05 and 0.80 for lubricated and dry interfaces. In the present case, the interface was lubricated. Hwang and Zum Gahr [14] reported a friction coefficient to be around 0.10 for a lubricated interface. Knight [15] supports this value for a coefficient ranging from 0.05 to 0.10 . However, an engineering database suggests a coefficient of 0.16 [16]. Within this study, the high temperature and the unpolished surfaces may be the reason for the slightly high friction coefficient values.

\subsection{Characterization of the paste/steel friction coefficient}

This section focuses on the characterization of the friction at the interface of the carbon paste and friction plate. The tribological behaviour was obtained and validated using the two methods described in Section 2.4.

In order to obtain the paste/steel friction coefficient, two series of tests are required: the series used to illustrate the influence of the applied load that gives $F_{\mathrm{T}}$ (second part of the Section 3.1) and a similar test with one different boundary condition that gives $F_{\mathrm{T} 1}$. In this case, the square steel layer was added under the paste. Thus, the applied load is transmitted to the friction plate through the steel and Teflon. The applied loads used for the second series were ranging from 2.85 to $31.37 \mathrm{kN}$. The values used to determine the static and kinetic friction forces have been extracted following the same procedure than that used in Section 3.2.

Figure 20 presents the friction force as a function of the applied load. In this graph, the traction force $\left(F_{\mathrm{T} 1}\right)$ presents a linear behaviour with the applied load and the static coefficient is higher than the kinetic one, as expected.

The method used to validate the obtained coefficients refers to a series of tests that gives $F_{\mathrm{T} 2}$. For these tests, the steel and Teflon layers were interchanged. Thus, the Teflon layer is placed under the paste and the steel under the mould. Within this approach, the starred steel/steel ${ }^{*}$ friction coefficients $\left(\mu_{\mathrm{s} / \mathrm{s}^{*}}\right)$ were used due to the similar stick-slip behaviours with the series of tests that gives $F_{\mathrm{T} 2}$.

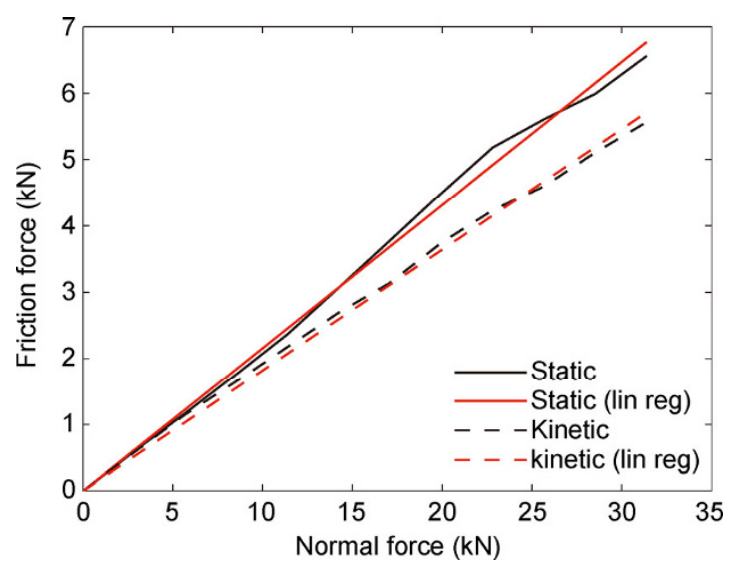

Fig. 20 Traction force (actuator B) of the "inside steel and outside Teflon layers" versus normal applied load.

This series presents 13 tests with the applied load ranging from of 2.85 to $37.05 \mathrm{kN}$. Figure 21 presents the traction forces $\left(F_{\mathrm{T} 2}\right)$ as a function of the normal applied load and the regression lines are presented with the red lines. The static curve is higher than the kinetic one as it was usually the case. The friction force curves present some outliners. However, the tendencies are enough evident to adequately apply the regression used for validating the previously obtained paste friction coefficients (based on $F_{\mathrm{T} 1}$ ).

The static and kinetic paste friction coefficients have been evaluated according to the two methods. The performed series of tests within Sections 3.2 and 3.3 were used to characterize the friction coefficients $\left(\mu_{\mathrm{T} / \mathrm{s} s}, \mu_{\mathrm{s} / \mathrm{s}}\right.$ and $\left.\mu_{\mathrm{s} / \mathrm{s}^{*}}\right)$ and to identify the traction forces $\left(F_{\mathrm{T} 1}\right.$ and $\left.F_{\mathrm{T} 2}\right)$. The traction force $\left(F_{\mathrm{T}}\right)$ was taken from the series of tests related to the influence of the applied load (second part of Section 3.1). The carbon

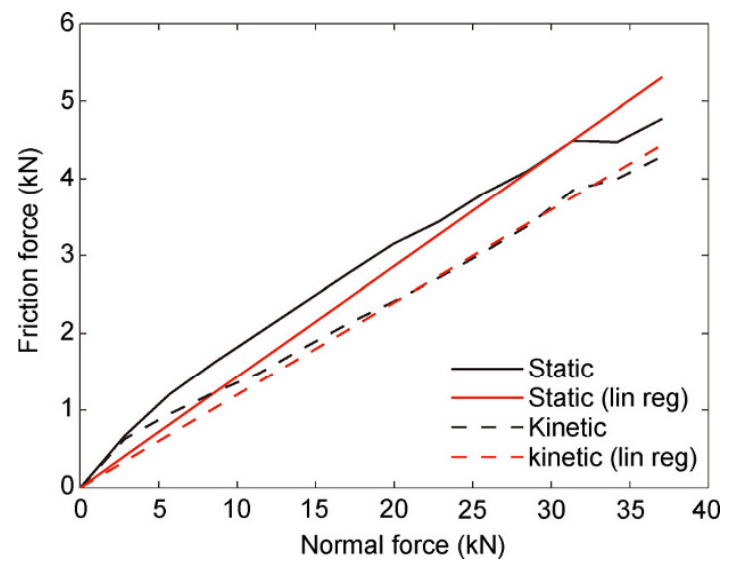

Fig. 21 Traction force (actuator B) of the "inside Teflon and outside steel layers" versus normal applied load. 
paste friction coefficients were determined for each applied force $\left(F_{\text {app }}\right)$ according to the Eqs. (10) and (14). The static and kinetic paste friction coefficients were calculated separately. The calculations were performed for each applied force $\left(F_{\text {app }}\right)$ using the corresponding traction forces ( $F_{\mathrm{T}}$ with $F_{\mathrm{T} 1}$ or $F_{\mathrm{T} 2}$, depending of the case).

Figure 22 shows the paste friction coefficients as a function of the applied load based on the measured traction forces. The black curves represent the method using the steel layer inside and the Teflon layer outside. The red curves represent the case with the inverted layers: Teflon inside and steel outside. The static and kinetic coefficients are represented with a full and dash lines, respectively.

The friction coefficients from the two methods are relatively well superposed. The higher friction coefficients at very low applied load might be caused by the bearing restriction, which is not negligible compared to the traction force. In addition, normal loads smaller than $5 \mathrm{kN}$ are at the lower limits of the load cells (maximum capacity of $250 \mathrm{kN}$ ) which might result in higher errors in recording the forces. The coefficients reach a plateau starting at a normal applied force of $10 \mathrm{kN}$.

On the other hand, the paste friction coefficients were calculated from the linear regressions (Figs. 20 and 21). The calculated values become constant and correspond to the mean values of the plateaus. The friction coefficients of the steel/paste interface are presented within the Table 2.

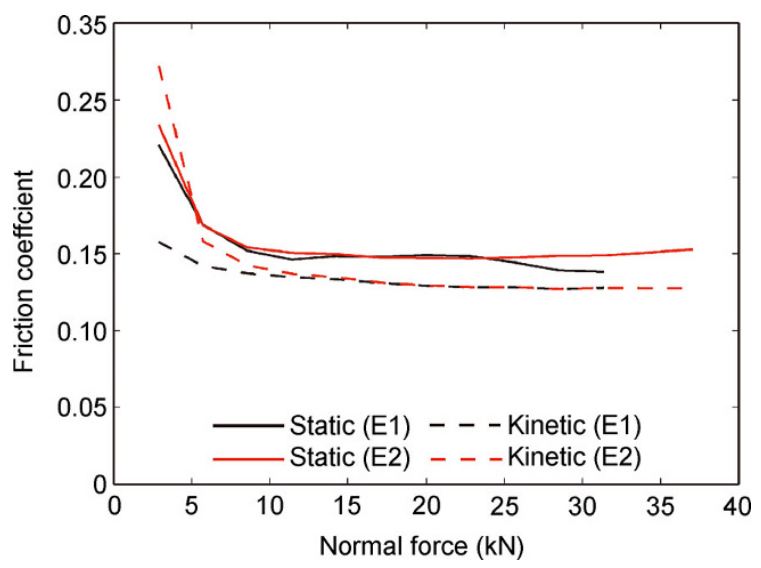

Fig. 22 Paste static and kinetic friction coefficients according to the first and second methods.
Table 2 Steel/paste friction coefficients calculated from the linear regression.

\begin{tabular}{lll}
\hline & $\mu_{\text {static }}$ & $\mu_{\text {kinetic }}$ \\
\hline Approach 1: $F_{\mathrm{T}}$ versus $F_{\mathrm{T} 1}$ & 0.145 & 0.129 \\
Approach 2: $F_{\mathrm{T}}$ versus $F_{\mathrm{T} 2}$ & 0.150 & 0.129 \\
\hline
\end{tabular}

\section{Conclusions}

The aim of this investigation was to determine the friction coefficients (static and kinetic) of the carbon paste against steel at $150{ }^{\circ} \mathrm{C}$ and high stress levels. This coefficient is an important data for simulation of compaction of carbon anode paste in aluminium industry. An apparatus and comparative method were developed. Teflon/steel and steel/steel friction coefficients were measured. The two comparative series of tests were performed to determine and validate the paste/steel friction coefficient.

The first results presented in this paper show that, within an interval from 2 to $20 \mathrm{~mm} / \mathrm{s}$, the relative velocity between the paste and the steel plate has no significant influence on the friction behaviour. However, the normal applied force correlates linearly with the friction. This suggests that the real paste area in contact with the steel plate does not significantly evolve within an applied load ranging from 0.5 to $6.5 \mathrm{MPa}$. These two observations confirmed that the Coulomb friction model was judiciously chosen and made reasonable estimation of the friction behaviour.

The Teflon and steel friction coefficients were measured using strategies that give the exact applied load at the interface. The tests were performed at the same temperature and with the same lubrication method as for the entire investigation. The static and kinetic friction coefficients for Teflon/steel interface $\left(\mu_{\mathrm{T} / \mathrm{s}}\right)$ are 0.17 and 0.13 , respectively. The steel/steel friction coefficients $\left(\mu_{\mathrm{s} / \mathrm{s}}\right)$ were measured twice due to a stick-slip behaviour. The measured coefficients obtained with the first setup, which was more appropriated, are 0.30 and 0.25 .

The two approaches used to characterize and validate the paste friction behaviour coefficients gave sensibly the same results. The similarities suggest that the method developed to determine the paste/steel coefficient is efficient. These approaches used the appropriate steel/steel friction coefficients according 
to stick-slip behaviour. The results show that the paste/steel friction coefficients are higher at low applied load and reach a plateau at higher applied load (around $10 \mathrm{kN}$ ). The paste/steel coefficients were also evaluated according to the regression curves of the two comparative series of tests giving a mean static and kinetic friction coefficients of 0.15 and 0.13 . These values correspond to the plateau observed in Fig. 22.

\section{Acknowledgments}

Authors would like to acknowledge the financial support of Natural Sciences and Engineering Research Council (NSERC) and Alcoa. A part of the research presented in this paper was financed by the Fonds de recherche du Québec-Nature et technologies (FRQ-NT) by the intermediary of the Aluminium Research Centre-REGAL. Particular thankfulness is dedicated to Hugues Ferland, from the REGAL group at Laval University, and Nicolas Turcotte for their help in the development of the apparatus and the execution of the tests in laboratory.

\section{List of symbols}

$f_{\mathrm{F}} \quad$ Global friction force

$f_{\mathrm{p}} \quad$ Paste friction force

$f_{\mathrm{s}} \quad$ Steel friction force

$f_{\mathrm{T}} \quad$ Teflon friction force

$F_{\text {app }}$ Applied force

$F_{\mathrm{T}} \quad$ Traction force of the paste friction tests

$F_{\mathrm{T} 1} \quad$ Traction force of the first reference tests

$F_{\mathrm{T} 2} \quad$ Traction force of the second reference tests

$\mu_{\mathrm{p} / \mathrm{s}} \quad$ Paste/steel friction coefficient

$\mu_{\mathrm{s} / \mathrm{s}} \quad$ Steel/steel friction coefficient of the empty square layer

$\mu_{\mathrm{s} / s^{*}}$ Steel/steel friction coefficient of the two layers

$\mu_{\mathrm{T} / \mathrm{s}}$ Teflon/steel friction coefficient

$N \quad$ Normal force

$R_{\mathrm{m}} \quad$ Reaction of the friction plate according to the mould

$R_{\mathrm{p}} \quad$ Reaction of the friction plate according to the paste

Open Access: This article is distributed under the terms of the Creative Commons Attribution License which permits any use, distribution, and reproduction in any medium, provided the original author(s) and source are credited.

\section{References}

[1] Hulse K L. Anode Manufacture: Raw Materials Formulation and Pressing Parameters. Sierre (Switzerland): R\&D Carbon ltd., 2000.

[2] Keller F, Sulger P O. Anode Baking: Baking of Anodes for the Aluminum Industry. Sierre (Switzerland): R\&D Carbon ltd., 2008.

[3] Meier M W. Cracking: Cracking Behaviour of Anodes. Sierre (Switzerland): R\&D Carbon ltd., 1996.

[4] Hume S M. Influence of Raw Material Properties on Reactivity of Carbon Anodes. Auckland (New Zealand): AluminiumVerlag., 1993.

[5] Chaouki H, Thibodeau S, Alamdari H, Ziegler D, Fafard M. Modeling and simulation of green anode forming process. In Proceedings of the 50th Annual Conference of Metallurgists (COM 2011), Montréal, Canada, 2011: 2-5.

[6] Pierret J C, Rassili A, Vaneetveld G, Bigot R, LecomteBeckers J. Friction coefficients evaluation for steel thixoforging. Int J Mater Form 3: 763-766 (2010)

[7] Karnopp D. Computer-simulation of stick-slip friction in mechanical dynamic-systems. J Dyn Syst-T ASME 107(11): 100-103 (1985)

[8] Dahl P. A solid friction model. Technical Report TOR0158H3107-18I-1. The Aerospace Corporation, El Segundo, CA, 1968.

[9] Armstrong-Hélouvry B, Dupont P, De Wit C C. A survey of models, analysis tools and compensation methods for the control of machines with friction. Automatica 30(7): 10831138 (1994)

[10] Dowson D. History of Tribology $2^{\text {nd }}$ Ed. Suffolk (UK): Professional Engineering Publishing, 1998.

[11] Thibodeau S, Alamdari H, Ziegler D, Fafard M. New insight on the restructuring and breakage of particles during uniaxial confined compression tests on aggregates of petroleum coke. Powder Technol 253: 757-768 (2014)

[12] Azari K, Alamdari H, Aryanpour G, Picard D, Fafard M, Adams A. Mixing variables for prebaked anodes used in aluminum production. Powder Technol 235: 341-348 (2013)

[13] International Association of Plastic Distribution (iapd). http://www.iapd.org/bookstore/property_tables/fluoropolym ers.pdf, 2013. 
[14] Hwang D-H, Zum Gahr K-H. Transition from static to kinetic friction of unlubricated or oil lubricated steel/steel, steel/ceramic and ceramic/ceramic pairs. Wear 255: 365-375 (2003)

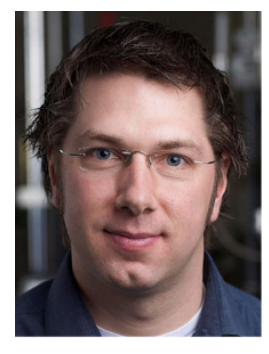

Stéphane THIBODEAU. He is a $\mathrm{PhD}$ candidate at the Civil and Water Engineering Department, Université Laval, Canada. His PhD research focuses on the modeling of the carbon paste forming process under the supervision of Dr. Mario

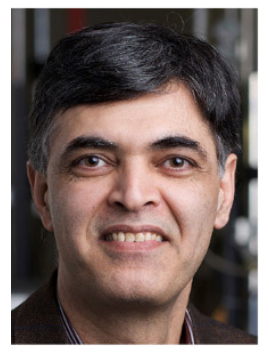

Houshang ALAMDARI. He received his MS degree in 1996 and $\mathrm{PhD}$ degree in 2000 from Université Laval, Canada. He pursued his research activities at Hydro-Québec research institute, Canada on synthesis of nanocrystalline materials for hydrogen storage. He held the process director position at Nanox Inc, Canada and

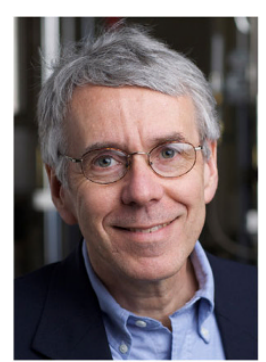

Donald ZIEGLER. He is program manager for Modeling of Alcoa Primary Metals. Having completed his Ph.D at the University of California, Berkeley and a post-doc

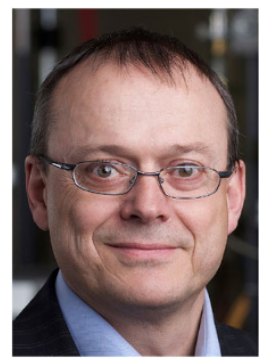

Mario FAFARD. He is a professor at Université Laval since 1987. He is the holder of the NSERC/Alcoa Industrial Research Chair at the Civil and Water Engineering Department.
[15] Knight D R. Physics for Scientists and Engineers: A Strategic Approach $2^{\text {nd }}$ Ed. San Fransisco (US): P. A. Wesley, 2008.

[16] The Engineering ToolBox. http://www.engineeringtoolbox.com/ friction-coefficients-d_778.html, 2012.

Fafard, Dr. Houshang Alamdari and Dr. Donald Ziegler. He obtained a Technical degree in Engineering Physics at La Pocatière College, Canada. He pursued his bachelor degree from the Department of Physic Engineering (2006) and his master degree from Department of Mining, Metallurgy and materials Engineering (2009), Université Laval, Canada.

was involved in development and scale up of a production process for nanostructured perovskite-type materials for automotive catalysts. In 2006, he joined Laval University as professor at Department of Mining, Metallurgy and materials Engineering, Université Laval, Canada. He is currently director of REGALLaval research center where his research activities are focused on aluminium production process.

at MADYLAM in Grenoble, he has been with Alcoa for 27 years. His research interests were initially in modeling of MHD phenomena in Hall cells, but he is increasingly involved in modeling applications in Hall cell structures and anode forming.

His main research interests are in the areas of advanced numerical modeling of aluminium cell, and thermomechanical testing on refractory materials at high temperature. 